\title{
ESTUDO SOBRE A PRODUTIVIDADE PRIMÁRIA DE UMA ESTAÇÃO FUNDEADA NO ESTUÁRIO DO RIO CURU (CEARA-BRASIL), NO PERIODO DE SETEMBRO DE 1977 A MAIO DE 1978
}

\author{
VERA LUCIA MOTA KLEIN \\ MARIA ACY MOURA FRANCA \\ Laboratório de Ciências do Mar, Universidade Federal do Ceará. Fortaleza, CE, Brasil
}

\begin{abstract}
SYNOPSIS
The study of primary production from phytoplankton in estuarine regions is of basic importance, to projects of culture of oysters. shrimps and fishes. In this paper a study was made of the primary production in the Rio Curi's estuary (Ceard-Brasil), during the period from September, 1977 to May, 1978. We used the Winkler's method to make the measurement of productions. The data obtained on oxygen pro. duced varied from 0.03 to $0.04 \mathrm{~m} \ell_{2} \mathrm{O}_{2}|\ell|$ hour of light, for net production and 0.01 to $0.04 \mathrm{~m} \ell \mathrm{O}_{2}|\ell|$ hour of light for the total production. Qualitative and quantitative studies were also made to obtain the dominant species and the most abundant and most frequent species.
\end{abstract}

\section{Introdução}

Atualmente, quando as vistas estão voltadas para um aproveitamento racional das disponibilidades alimentares e energéticas, o estudo da produtividade primária pelo fitoplâncton, em estuários, torna-se da maior importância, quando se visa fornecer subsídios para projetos de aqüicultura, nos cultivos de ostras, camarões e peixes.

O Rio Curú nasce na parte setentrional da serra do Machado e, depois de um curso muito sinuoso, orientado de SSO para NNE, despeja no oceano, onde forma um pequeno estuário. A bacia mede $6.761 / \mathrm{km}^{2}$ e o desenvolvimento do rio principal eleva-se 220 quilômetros (Pompeu Sobrinho, 1962).

Como os demais no Nordeste brasileiro, o Rio Curú é influenciado pelo regime pluvial; sua vazão é variável, apresentan do suas descargas máximas no período chuvoso (janeiro-julho), durante o período de estiagem (agosto-dezembro), sofre maior influência das marés. A relativa importância de seu estuário se deve à sua produção de camarões da espécie Penaeus schmitt Burkenroad, 1936 e de ostras da espécie Crassostrea rhizophorae (Guildilg, 1828), ambas muito apreciadas pelo mercado consumidor.

Durante o período de setembro de 1977 a maio de 1978 , foram efetuadas coletas, em uma estaçāo fundeada no estuário do Curú, tendo como objetivos a determinação da produtividade primária e o conhecimento do plâncton local.

\section{Material e Métodos}

Este estudo foi baseado nos dados referentes a 14 excursões realizadas ao estuário do Rio Curú, durante o período de setembro de 1977 a maio de 1978.

Os métodos por nós empregados nem sempre foram os considerados ideais, mas os que dispunhamos no momento.

As amostras foram obtidas com o auxílio de garrafa de Nansen; as medidas de produção primária foram feitas baseadas na produção de oxigênio, utilizando-se o método de Winkler (Strickland \& Parsons, 1960).

Após a determinação do oxigênio inicial, procedemos nova coleta de água, fazendo-se em seguida a incubação "in situ" das garrafas (clara e escura), por 12 horas a uma profundidade que variou de 1,60 a $4,30 \mathrm{~m}$, dependendo das condiçōes de marés. As garrafas ficaram suspensas por meio de uma forquilha de madeira.

Efetuamos coletas de superfície e de fundo ainda com a garrafa de Nansen, para determinações de salinidade, $\mathrm{pH}$ e temperatura, bem como para os estudos quanto-qualitativos do plâncton local.

A salinidade foi determinada com auxílio de densímetros, usando-se o fator de correção de temperatura; o pH com o papel indicador Carlo Erba e a temperatura por meio de termômetros de inversão acopłađas à garrafa de Nansen.

Para as análises quanto-qualitativos as amostras após fixadas em formol a $4 \%$ neutralizado com bórax, foram decantadas em provetas graduadas durante 24 horas; terminado este período, fizemos a leitura direte do volume de plâncton decantado e reduzimos a amostra (água + fixador + plâncton) para um volume padrão de $50 \mathrm{ml}$, sendo posteriormente homogeneizado e retirada uma aliquota de $1 \mathrm{~m} \ell$, para contagem total do microplâncton.

Procedemos à identificaça com auxilio de bibliografia especializada (ref. n! s $1-11,13,15-19$ ) e contagem em microscópio ótico binocular.

Os cálculos de número de células, colônias ou organismos por litro, foram feitos mediante uma série de 3 regras de três simples. Após os cálculos de número de colônia por litro, estimamos o número de células por colônia, para elaboração dos gráficos.
Em virtude da grande variedade de espécies existentes, utilizamos os seguintes critérios para apresentação dos resultados: espécies abundantes - espécies com ocorrência maior ou igual a $10 \%$ do fitoplâncton por dia de coleta:

espécies dominantes - aqueias que apresentassem uma ocorrência correspondente no mínimo ao dobro das espécies abundantes; espécies freqüentes - as que ocorreram no mínimo em $50 \%$ das coletas.

Os dados referentes às contagens, servirão apenas para dar uma idéia da participação de cada espécie no total do plâncton examinado, nâo se prestando para estudos comparativos com a produção, já que não foi calculado o volume de cada espécie encontrada.

\section{Resultados e Discussão}

Os dados referentes à hidrologia local, revelaram uma temperatura média de $26,28^{\circ} \mathrm{C}$, mantendo-se praticamente constante durante todo o período de amostragem, tanto nas coletas de superfície como nas de fundo, o que nos leva a acreditar que havia uma mesclagem em toda a coluna d'água; a salinidade média correspondeu a $22,7 \%$ oo tendo variado de 3,6 a $32,4 \%$ esta variação se deve à mudança dos regimes de chuvas e influência das condições de marés; o pH teve um valor médio de 8,1 , com um mínimo de 7,3 e um máximo de 8,8 ; a quantidade média de oxigênio dissolvido na água foi de $8,58 \mathrm{ml} / \ell$, com um mínimo de $6,4 \mathrm{~m} \ell / \ell$ e um máximo de $9,7 \mathrm{~m} \ell / \ell$ (Tab. I, Fig. 1).

Os valores de $\mathrm{O}_{2}$ produzido, utilizados como medida de produção, foram os seguintes:

\begin{tabular}{|c|c|c|c|}
\hline $\begin{array}{l}\text { Valores } \\
\text { Produções }\end{array}$ & Média & Mínimo & Máxim \\
\hline Prod. aparente & $\begin{array}{l}0,25 \mathrm{~m} \ell \mathrm{O}_{2} \\
|\ell| \text { hora-luz* }\end{array}$ & $\begin{array}{l}0,03 \mathrm{mlO}_{2} \\
|\ell| \text { hora-luz * }\end{array}$ & $\begin{array}{l}0,40 \mathrm{~m} \ell \mathrm{O}_{2} \\
|\ell| \text { hora-luz* }\end{array}$ \\
\hline Prod. total & $\begin{array}{l}0,33 \mathrm{~m} \ell \mathrm{O}_{2} \\
|\ell| \text { hora-luz * }\end{array}$ & $\begin{array}{l}0,10 \mathrm{~m} \ell \mathrm{O}_{2} \\
|\ell| \text { hora-luz* }\end{array}$ & $\begin{array}{l}0,45 \mathrm{~m} \ell \mathrm{O}_{2} \\
|\ell| \text { hora-luz * }\end{array}$ \\
\hline
\end{tabular}

* hora de luminosidade

A baixa produção de $0_{2}$, referido no limite mínimo se deveu ao fato das garrafas, por ocasião da incubação, terem permanecido por baixo da vegetação de mangue, fato este, observado somente, quando as mesmas foram retiradas. As produções máximas ocorreram no período chuvoso (Tab. I, Fig. 4).

O fitoplâncton presente, mostrou-se muito variado, mas com poucas espécies dominantes (Tab. III).

As classes que compuseram o fitoplâncton local foram: Chlorophyceae, Bacillariophyceae e Myxophyceae (Tab. II).

Classe Chlorophyceae-esteve presente com 19 espécies pertencentes a 15 gêneros, sua participação mais expressiva foi nas últimas coletas, ocasião em que a salinidade apresentou seus mais baixos valores. Com relação à freqüência de incidência, esteve ausente em duas coletas de superfície e em três de fundo. As espécies desta classe consideradas abundantes foram:Coeglastrum sp. Dictiospharium sp., Pediastrum sp., Planktosphaeria gelatinosa, Protococcus sp., Scepedesmus acuminatus, Scenedesmus quadricauda, Schizogonium sp. e Ulothrix sp. a única espécie dominante da classe foi Planktosphaeria gelatinosa e a mais freqüente, Ulothris $\mathrm{sp}$.

Classe Bacillariophyceae - foi a classe mais variada, contando com a participação de mais de 99 espécies, pertencentes a 42 gêneros; sua abundância revelou quase sempre como a mais representativa; em freqüência, esta foi a única classe presente em todas as amostras analisadas quer de superfície ou de fundo. 
As espécies consideradas abundantes toram: Asterionella japonica, Bellarochea sp., Chaetoceros sp. Coscinodiscue commutatus, Cy. clotella striata, Gyrosigma hippocampus Melosira mummuloides, Nitzschia seriata. Thalassionema sp. Thalassiosira sp. e Thalassiothrix sp.. as mais freqüentes foram: Amphora sp. Asterionella japonica, Bacillaria sp., Chaetoceros sp. Cocconeis paniformis,
Coscinodiscus commutatus, Fragilaria sp., Gyrosigma hippocampus, Melosira mummuloides, Melosira sulcata, Navicula bombiformis, Navicula hyalina, Navicula sp., Nitzschia lanceolata; Nitzschia longissima. Nitzschia sp., Rhizosolenia sp.. Skeletonema costatum e Thalassiothrix sp. As consideradas dominantes foram:Melosira nummuloides, Coscinodiscus commutatus e Asterionella japonica.

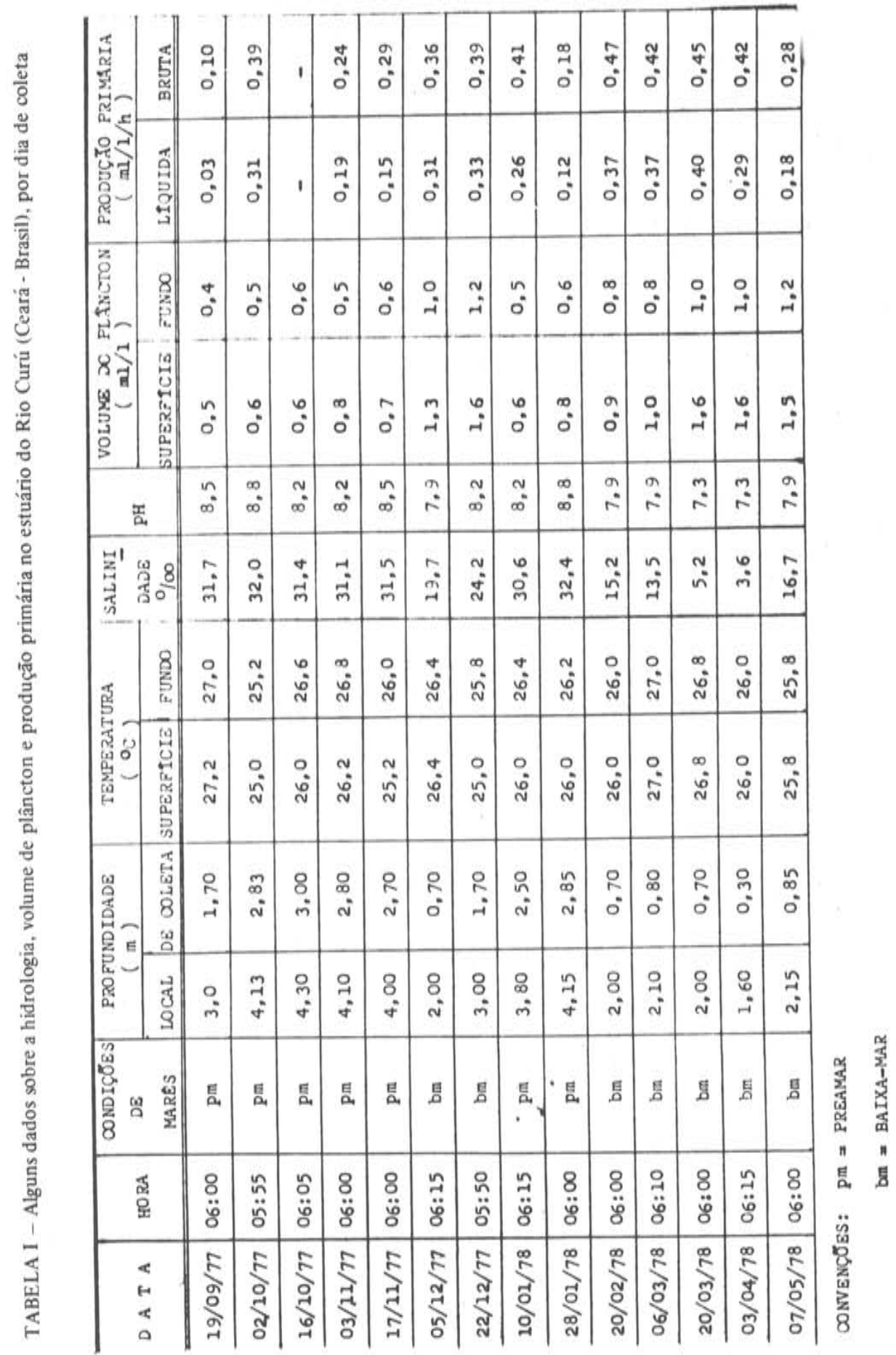




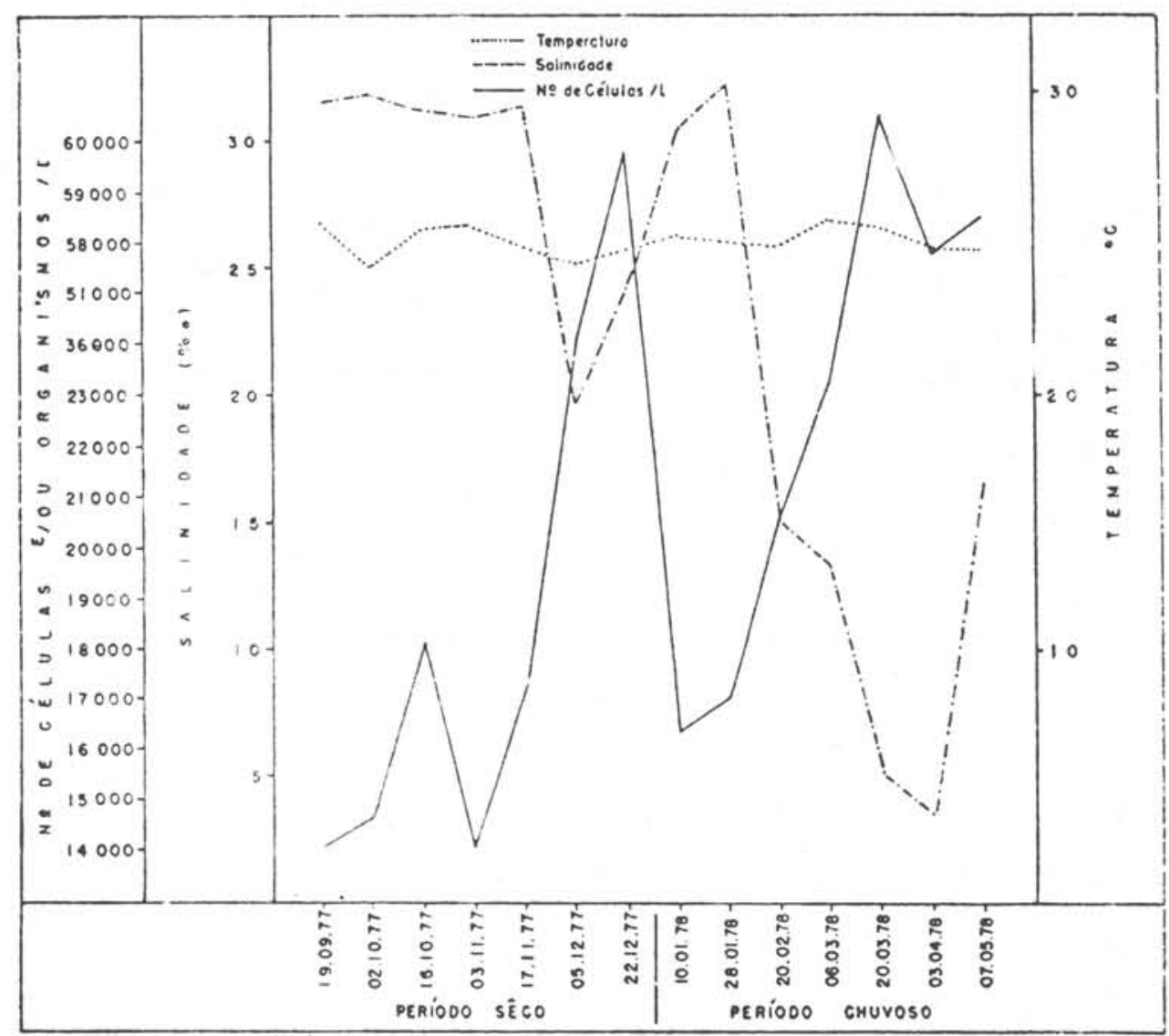

Fig. 1 - Alguns dados sobre a hidrologia do estuário do Rio Curú (Ceará - Brasil), durante o período setembro 77 - maio 78, relacionados com o número de células e/ou organismos por litro do plâncton.

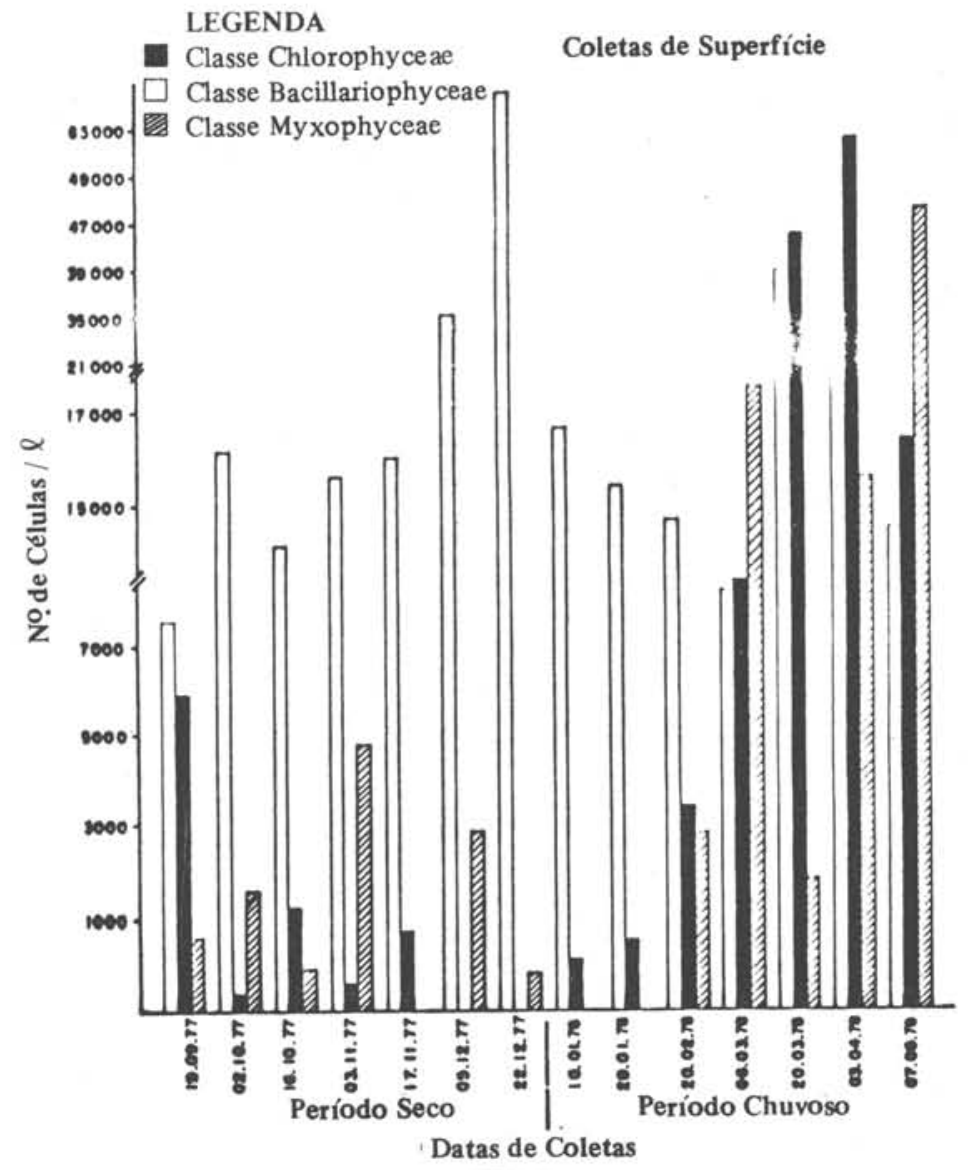

Fig. 2 - Participação das diferentes classes do fitoplâncton de superfície, no estuário do Rio Curú (Ceará - Brasil) durante o período setembro 77 - maio 78 . 


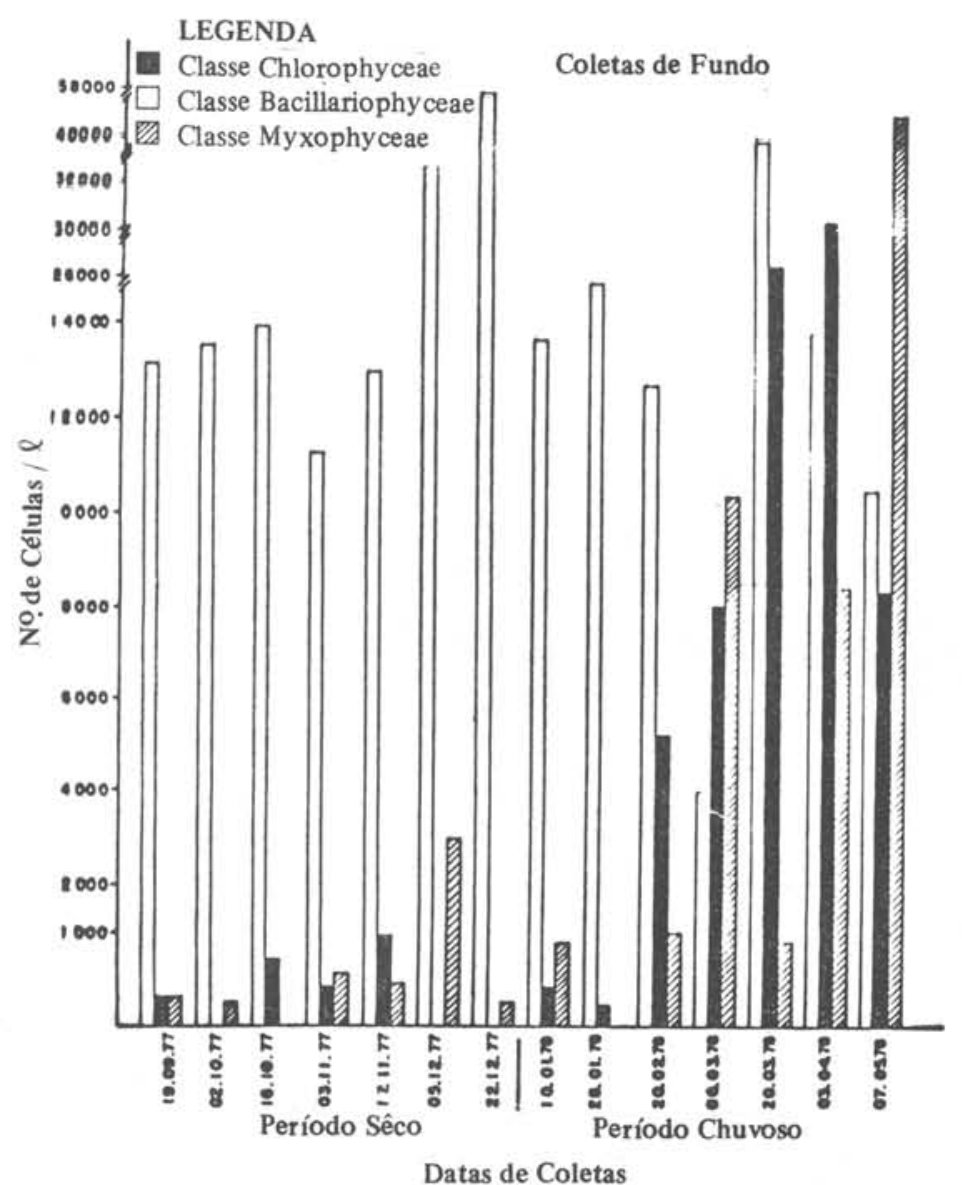

Fig. 3 - Participação das diferentes classes do fitoplâncton de fundo, no estuário do Rio Curú (Ceará - Brasil), durante o período setembro 77 - maio 78 .

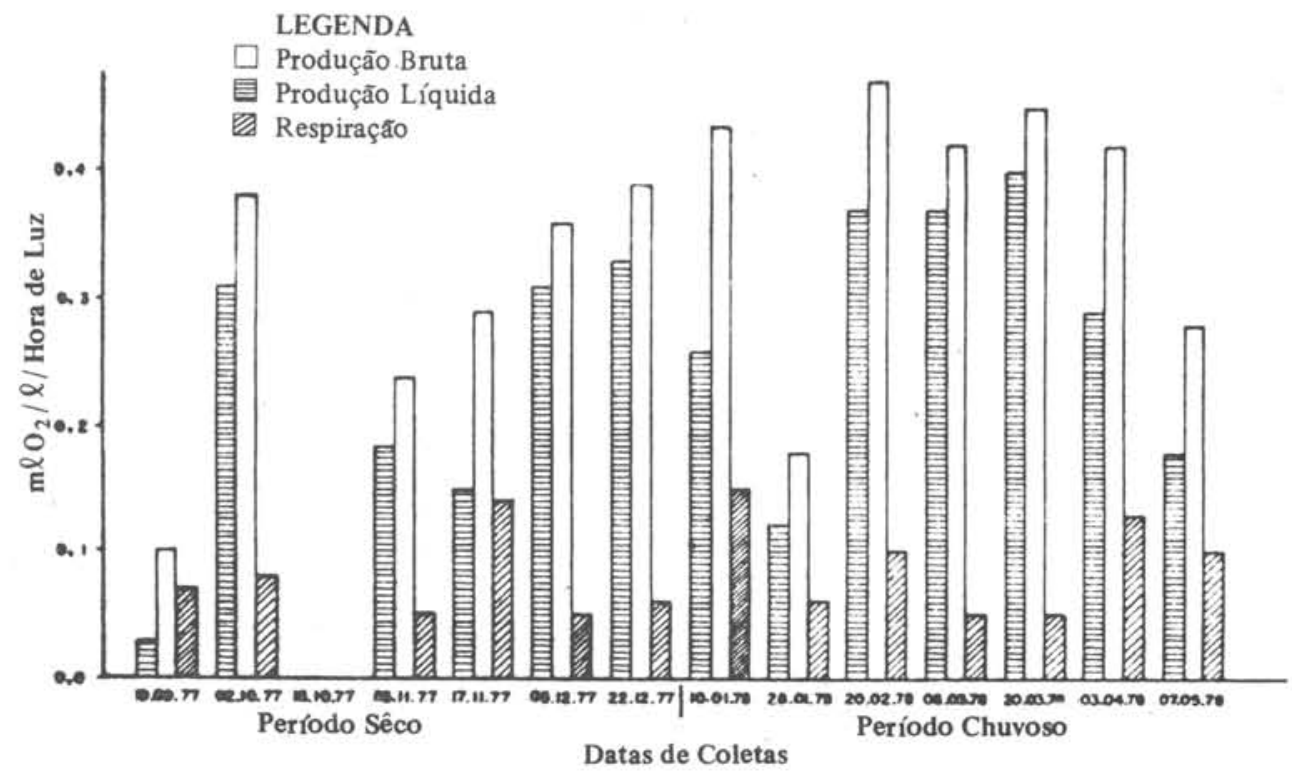

Fig. 4 - Dados referentes à produção primária no estuário do Rio Curú (Ceará - Brasil), durante o período setembro 77 - maio 78. 


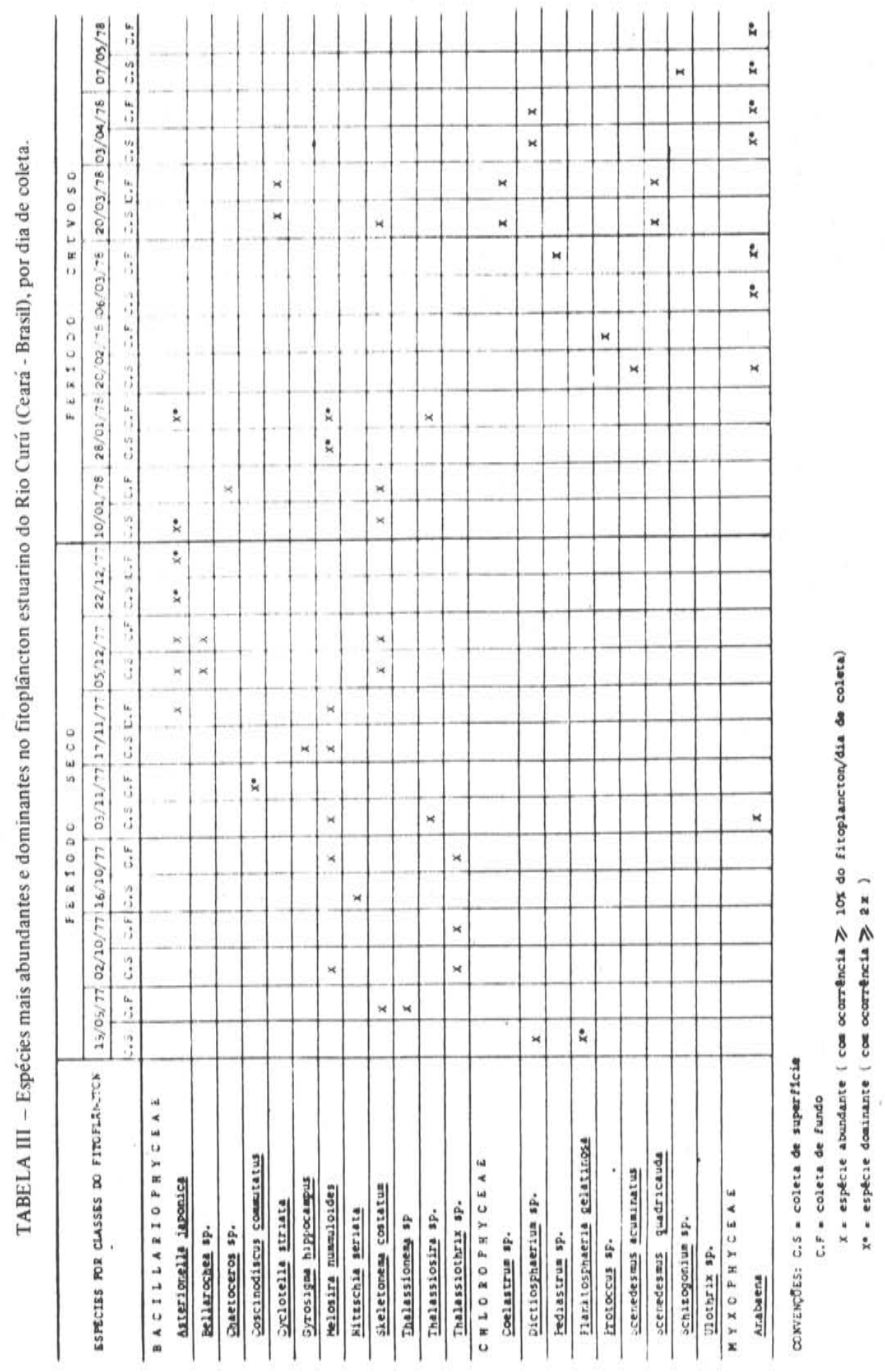




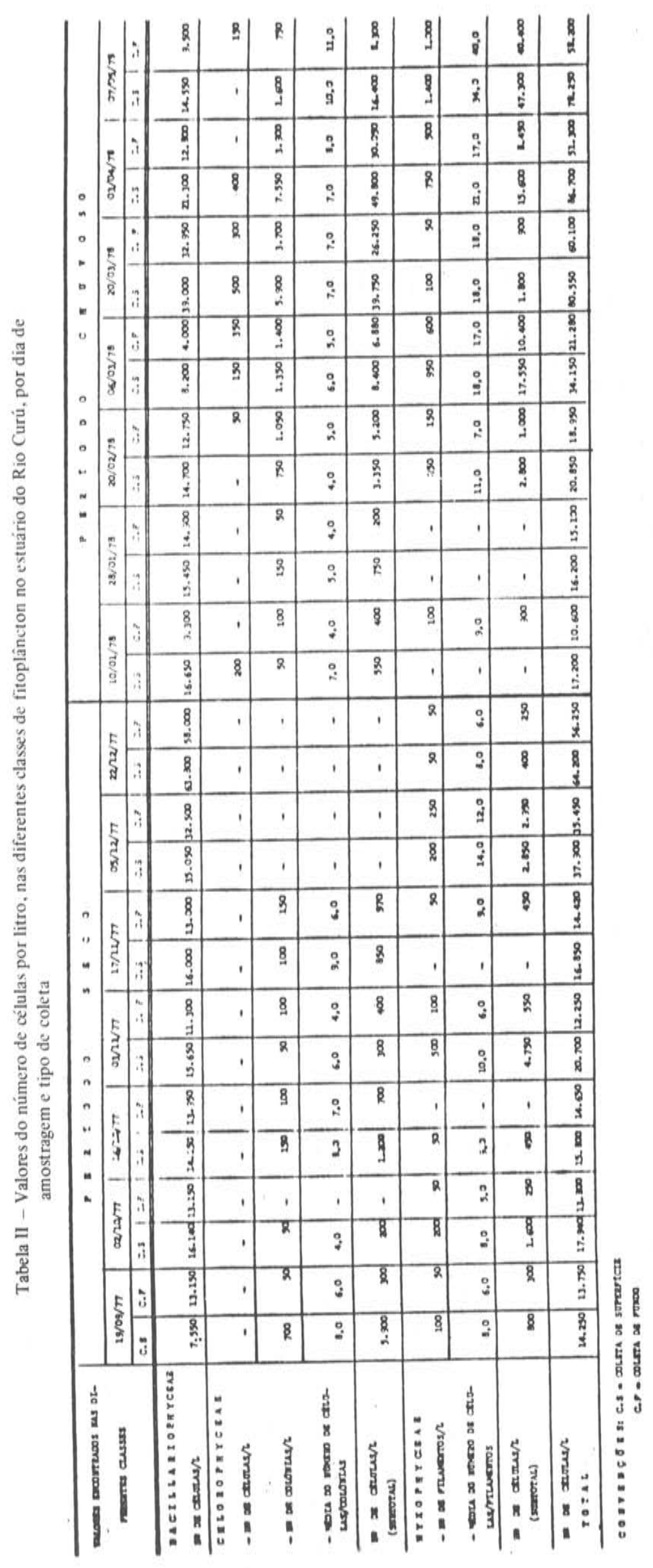


Classe Myxophyceae-foi a que apresentou a menor variedade de representantes, com apenas quatro gêneros; dos presentes, apenas Anabaena foi considerado abundante, tendo sido, dominante em algumas coletas e o único com freqüência superior a $50 \%$ das coletas.

Os valores máximos de número de células por litro, para a classe Bacillariophyceae ocorreram no período de estiagem para os dois tipos de coleta (superficie e fundo); entretanto as classes Chlorophyceae e Myxophyceae apresentam uma maior quantidade de células por litro no período chuvoso, tanto para as coletas de superfície como as de fundo (Tab. II, Figs. 2 e 3 ).

Das espécies presentes no fitoplâncton total, verificamos que algumas delas, ocorreram em um único dia de coleta $€$ com participação irrelevante, outras tiveram uma ocorrência regular mas numericamente inexpressivas e aquelas que participaram de modo efetivo tanto em freqüência como em abundância.

Foi observado que, no decorrer do período de coletas. houve a substituição de espécies na ordem de abundância, che. gando algumas vezes mesmo, ao completo desaparecimento nas amostras analisadas, isto talvez explique pela estação do ano em que foi realizada a coleta, se no período de estiagem (julho-dezembro) ou no período chuvoso (agosto - dezembro).

A participação do zooplâncton nas amostras examinadas. foi quase sempre muito reduzida, sendo composto de elementos pertencentes aos filos: Protozoa (Radiolaria, Acantharia e Ciliata); Aschelminthes (Rotifera); Chaetognatha; Annelida (larvas de Polychaeta); Arthropoda exclusivamente com representantes da classe Crustacea: Copepoda (adultos, larvas e ovos), Cirripedia, Euphausiaceae e Decapoda (em estágio larvar): e Chordatha (ovos de peixes)

Procuramos relacionar a maior ocorrência do zooplâncton com o aumento no consumo de $0_{2}$ pela respiração, entretanto. verificamos que apenas uma vez esta relação foi válida.

\section{Conclusões}

O Rio Curú apresenta um regime de vazão influenciada pelas estações, chuvosa (janeiro-julho) e seca (agosto-dezembro).

Os dados hidrológicos demonstraram uma temperatura média de $26,28^{\circ} \mathrm{C}$, mantendo-se praticamente constante durante todo o período de amostragem, tanto nas coletas de superfície como nas de fundo, o que nos leva a concluir, que houve uma mesclagem em toda a coluna d'água. A salinidade variou de 3,6 a $32,4 \%$ oo sendo influenciada pelas condições de marés e regime de chuvas, os valores mínimos corresponderam às coletas no período chuvoso. $\mathrm{O}$ pH variou de 7,3 a 8,8

A produção primária líquida ou produção aparente variou de $0,03 \mathrm{ml} 0_{2} / \ell /$ hora de luminosidade a $0,40 \mathrm{~m} \ell 0_{2} / \ell /$ hora de luminosidade; a produção total ou produção bruta variou de $0,10 \mathrm{ml} \mathrm{O}_{2} / \ell /$ hora de luminosidade a $0,40 \mathrm{~m} \ell \mathrm{O}_{2} / \ell /$ hora de luminosidade.

O fitoplâncton esteve sempre em maior quantidade que o zooplâncton; as classes que o compuseram foram: Chlorophyceae, Bacillariophyceae e Myxophyceae. Observamos haver uma variedade muito grande de espécies havendo, entretanto, poucas espécies dominantes.

A classe Bacillariophyceae foi a mais variada e quase sempre, também a mais abundante do fitoplâncton, contando com a participação de 42 gêneros com mais de 99 espécies, a média de número de células por litro, por dia de coleta para esta classe foi de $21.300 \mathrm{cel} / \ell$, para coletas de superfície e de $17.975 \mathrm{cel} / \ell$, para coletas de fundo, com um mínimo de $7.550 \mathrm{cel} / \ell$ em coleta de superfície e de $4.000 \mathrm{cel} / \ell$ em coleta de fundo; os máximos valores obtidos foram $63.800 \mathrm{cel} / \ell$ e $58.000 \mathrm{cel} / \ell$ em coletas de superfície e fundo respectivamente.

A classe Chlorophyceae esteve presente com 19 espécies, pertencentes a 15 gêneros, sendo a segunda mais variada, seus componentes se apresentaram solitários ou formando colônias. No que diz respeito à abundância, apenas em um dia de coleta, sobrepujou em ocorrència as demais classes. Com relação à freqüência, esteve ausente em algumas coletas.

A classe Myxophyceae foi a que apresentou a menor variedade de representantes com apenas quatro gêneros.
Durante o período chuvoso houve um acréscimo nas espécies pertencentes às classes Chlorophyceae e Myxophyceae, tanto sob o ponto de vista qualitativo como no ponto de vista quantitativo.

As espécies dominantes do fitoplâncton foram Asterionella japonica, Coscinodiscus commutatus e Melosira nummuloides das Bacillariophyceae; Planktosphaeria gelatinosa das Chlorophyceae e o gênero Anabaena das Myxophyceae.

A participação do zooplâncton foi muito reduzida, os elementos encontrados pertenciam aos filos: Protozoa (Radiolaria, Acantharia e Ciliata); Aschelminthes (Rotifera); Chaetognatha; Annelida (larvas de Polychaeta); Arthropoda, exclusivamente com a classe Crustacea: Copepoda (adultos, larvas e ovos), Cirripedia, Euphausiaceae e Decapoda (em estágio larvar) e Chordatha (ovos de peixes).

\section{Bibliografia}

1. BICUDO, C.E.M. \& BICUDO, R.M.T. 1970. Algas das águas continentais brasileiras. São Paulo, Fund. Bras. Desenv. Ens. Ciênc., 228 p., 430 figs.

2. ESKINAZI, E. 1976. Estudo da Barra da Jangada. Parte V. Distribuição das diatomáceas. Trabhs. Inst. oceanogr. Univ. Fed. PE., 7/8:17-32, 3 figs.

3. FRITSCH, F.E. 1961. The structure and reproduction of the algae. $4^{\text {th }}$ ed. London, Cambridge Univ. Press, 791 p., 245 figs.

4. GRIFFITH, R.E. 1961. Phytoplankton of Chesapeake Bay. Chesapeake Biological Laboratory. Maryland Department of Research and Education, 172(1):1-79, 123 figs.

5. PERAGallo, H. \& PERAGALLO, M. 1897-1908. Diatomées marines de France et des districts maritimes voisins. Grez-sur-Loing, J. Tempère, 137 ests.

6. JOLY, A. B. 1963. Gêneros de algas de água doce da cidade de São Paulo e arredores. Rickia. S Paule $1: 1-100,125$ fies.

7. LICEA-DURAN, S. 1974. Sistematica e distribuición de diatomeas de la Laguna Agiabampo, Son/Sin., México. An. Centro Cienc. Mar Limnol. Univ. Nal Auton México, I(1) 99-156.

8. MOREIRA FILHO, H. 1961. Diatomáceas da Baía de Guaratuba. (Paraná-Brasil). Bolm Univ. Fed. Paraná, Bot., (3):1-35, 32 figs.

9. MOREIRA FILHO, H.; MARUO, Y.; MOREIRA, I.M.V. \& ESKINAZI-LEÇA, E, 1968. Diatomáceas da Lagoa Ōlho D'água (Estado de Pernambuco-Brasil). Bolm Univ. Fed. Paraná, Bot., (21):1-15. 22 figs.

10. NEWELL, R.C. \& NEWELL, G.E. 1963. Marine plankton, a practical guide. London, Hutchinson, 207 p.. 51 figs

11. PATRICK, R. 1959. Bacillariophyceae. In: Edmondson, W.T. ed. Fresh-water biology. 2nd ed. New York, John Wiley, ว. 171-189.

12. POMPEU SOBRINHO, T. 1962. Esboço fisiográfico do Ceará Fortaleza, Imprensa Universitária. 219 p.

13. SANTISTEVAN, R.J. 1976. Diatomeas y silicoflagelados del fitoplancton del Golfo de Guayaquil. Guayaquil, Inst. Oceanogr. de la Armada, 73 p., 19 ests.

14. STRICKLAND, J.D. H. \& PARSONS, T.R, 1960, A manual of sea water analysis (with special reference to the more common micronutrients and particulate organic material). Bull. Fish. Res. Bd Can., (125):1-185.

15. SUÁREZ-CAABRO, J,A. \& GOMEZ-AGUIRRE, S. 1965. Observaciones sobre el plancton de la Laguna de Términos, Campeche, México. Bull. mar. Sci., 15(4):1072-1120, 19 figs

16. TOMPSON, R.H. 1959. Algae. In:Edmondson, W.T., ed. Fresh -water biology. 2nd ed. New York, John Wiley.

17. TREGOUBOFF, G. \& ROSE, M. 1957. Manuel de planctologie méditerranéenne. Paris, Centre Nat Rec. Scient. 2 vol

18. WICKSTEAD, J. 1965. An introduction to the study of tropical plankton. London, Hutchinson, 159 D.. 181 figs.

19. WIMPENNY.R.S. 1966. The plankton of the sea. London, Faber \& Faber, 426 p., 100 figs. 